\title{
A smart single-chip micro-hotplate- based gas sensor system in CMOS-technology
}

\section{Journal Article}

\section{Author(s):}

Barrettino, Diego; Graf, Markus; Zimmermann, Martin; Hagleitner, Christoph; Hierlemann, Andreas (D); Baltes, Henry

\section{Publication date:}

2004-06

Permanent link:

https://doi.org/10.3929/ethz-b-000413460

Rights / license:

In Copyright - Non-Commercial Use Permitted

Originally published in:

Analog Integrated Circuits and Signal Processing 39(3), https://doi.org/10.1023/B:ALOG.0000029663.89451.a0 


\title{
A Smart Single-Chip Micro-Hotplate-Based Gas Sensor System in CMOS-Technology \\ DIEGO BARRETTINO, ${ }^{*}$ MARKUS GRAF, MARTIN ZIMMERMANN, CHRISTOPH HAGLEITNER, ANDREAS HIERLEMANN AND HENRY BALTES
}

Physical Electronics Laboratory, Swiss Federal Institute of Technology, Zurich, ETH Hoenggerberg, HPT H3, 8093 Zurich, Switzerland

E-mail: barrettino@iqe.phys.ethz.ch

Received November 18, 2002; Revised May 23, 2003; Accepted September 25, 2003

\begin{abstract}
This paper presents a monolithic chemical gas sensor system fabricated in industrial CMOS-technology combined with post-CMOS micromachining. The system comprises metal-oxide-covered $\left(\mathrm{SnO}_{2}\right)$ micro-hotplates

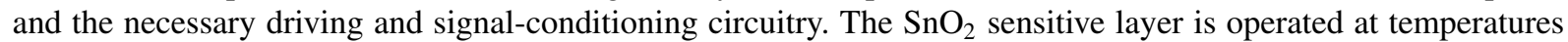
between 200 and $350^{\circ} \mathrm{C}$. The on-chip temperature controller regulates the temperature of the membrane up to $350^{\circ} \mathrm{C}$ with a resolution of $0.5^{\circ} \mathrm{C}$. A special heater-design was developed in order to achieve membrane temperatures up to $350^{\circ} \mathrm{C}$ with $5 \mathrm{~V}$ supply voltage. The heater design also ensures a homogeneous temperature distribution over the heated area of the hotplate (1-2\% maximum temperature fluctuation). Temperature sensors, on- and off-membrane (near the circuitry), show an excellent thermal isolation between the heated membrane area and the circuitry-area on the bulk chip (chip temperature rises by $\max 6^{\circ} \mathrm{C}$ at $350^{\circ} \mathrm{C}$ membrane temperature). A logarithmic converter was included to measuring the $\mathrm{SnO}_{2}$ resistance variation upon gas exposure over a range of four orders of magnitude. An Analog Hardware Description Language (AHDL) model of the membrane was developed to enable the simulations of the complete microsystem. Gas tests evidenced a detection limit below $1 \mathrm{ppm}$ for carbon monoxide and below $100 \mathrm{ppm}$ for methane.
\end{abstract}

Key Words: metal-oxide gas sensors, analog IC design, AHDL, CMOS compatible micromachining, microhotplates

\section{Introduction}

There is a strong interest in CMOS-based microsensors and, in particular, in micro-hotplate-based gas sensors, since miniaturization and the possibility of monolithic integration of transducer and circuitry offer significant advantages such as low power consumption, potentially low costs, and the possibility of applying new dynamic sensor operation modes.

Tin dioxide $\left(\mathrm{SnO}_{2}\right)$ is a widely used sensitive material for gas sensing in ambient air [1]. Tin dioxide is heated to temperatures between 200 and $350^{\circ} \mathrm{C}$ and changes its conductivity upon gas exposure. To achieve such high operation temperatures with the lowest possible power consumption, micro-hotplate structures have been developed for metal oxide gas sensors during the past few years [2-7]. A micro-hotplate consists of a thermally isolated area with a heater structure, a tem-

*Corrresponding author. perature sensor and contact electrodes for the sensitive layer. Many micro-hotplates were termed "CMOScompatible", but only a few have been produced in standard CMOS processes $[4,5,11-13,15]$.

Micro-hotplate-based gas sensors systems were implemented in a multi-chip approach [8-10], i.e., the micro-hotplates were placed on one chip, and the necessary driving and signal conditioning circuitry was hosted by a separate Application Specific Integrated Circuit (ASIC). First versions of monolithic microhotplate-based gas sensors systems were demonstrated in refs. [11-13]. It was established that integrating micro-hotplates and the corresponding circuitry on the same substrate is feasible without over-heating the electronics. Additional features of the monolithic solution include low power consumption, low noise, reliable electrical signals, high yield, and low production costs as compared to a multi-chip approach. The integration of multiple gas sensors in sensor arrays, the use of multi-component analysis algorithms, such as principal 
component regression (PCR) or artificial neural networks (ANN), and the application of new dynamic sensor operation modes $[14,15]$ help to overcome the problems associated with poor selectivity and drift of individual gas sensors [16].

In this paper we will give a detailed description of the monolithic chemical gas sensor, which was first reported on in [11], and we will present an outlook to future developments. The paper is organized in five sections. The overall description of the monolithic gas sensor system is given in Section 2, where the membrane and circuitry will be described in detail. The modeling of the membrane using AHDL and the simulation results of the overall system will be presented in Section 3. Experimental results, including electrical and chemical measurements, will be shown in Section 4. Conclusions and a brief outlook will be given in Section 5.

\section{System Description}

\subsection{Membrane}

Figure 1 shows a micrograph of the microsensor system. The chip was fabricated using a standard doublepoly, double-metal, $0.8 \mu \mathrm{m} \mathrm{CMOS-process} \mathrm{as} \mathrm{provided}$ by [17].

The chip hosts a micro-hotplate (close-up in Fig. 2), which is thermally isolated from the rest of the chip by placing it on a very thin membrane with low heat- conductivity. The membrane consists of the dielectric layers (silicon oxide/nitride) and features an additional $N$-well island (no connection to the bulk), which remains after applying a potassium-hydroxide $(\mathrm{KOH})$ wet-etch with an electrochemical etch stop [18]. After wet etching, the $\mathrm{SnO}_{2}$ sensitive layer is deposited on the membrane as a nanocrystalline thick film (crosssection in Fig. 3).

The membrane is 500 by $500 \mu \mathrm{m}$ in size with a heated area (micro-hotplate) of 300 by $300 \mu \mathrm{m}$. The heated area exhibits a $6 \mu \mathrm{m}$-thick $N$-well silicon island underneath for homogeneous heat distribution and membrane stiffening. The membrane features a polysilicon ring-heater, which provides symmetric heat generation and dissipation. Four resistive polysilicon temperature sensors (Fig. 2) are integrated on the membrane to monitor the heat distribution. The polysilicon temperature sensor located in the center of the membrane provides input for the temperature control circuitry. The experimentally assessed maximum temperature variation across the membrane is $1-2 \%$ up to $350^{\circ} \mathrm{C}$, and the membrane power efficiency is $4.8^{\circ} \mathrm{C} / \mathrm{mW}$. A more detailed description of the design considerations of the microhotplate is given in reference [19].

\subsection{Circuitry}

A schematic of the chip is shown in Fig. 4 as a block diagram. The circuitry can be grouped in three functional units: (i) Membrane temperature control loop, (ii) bulk

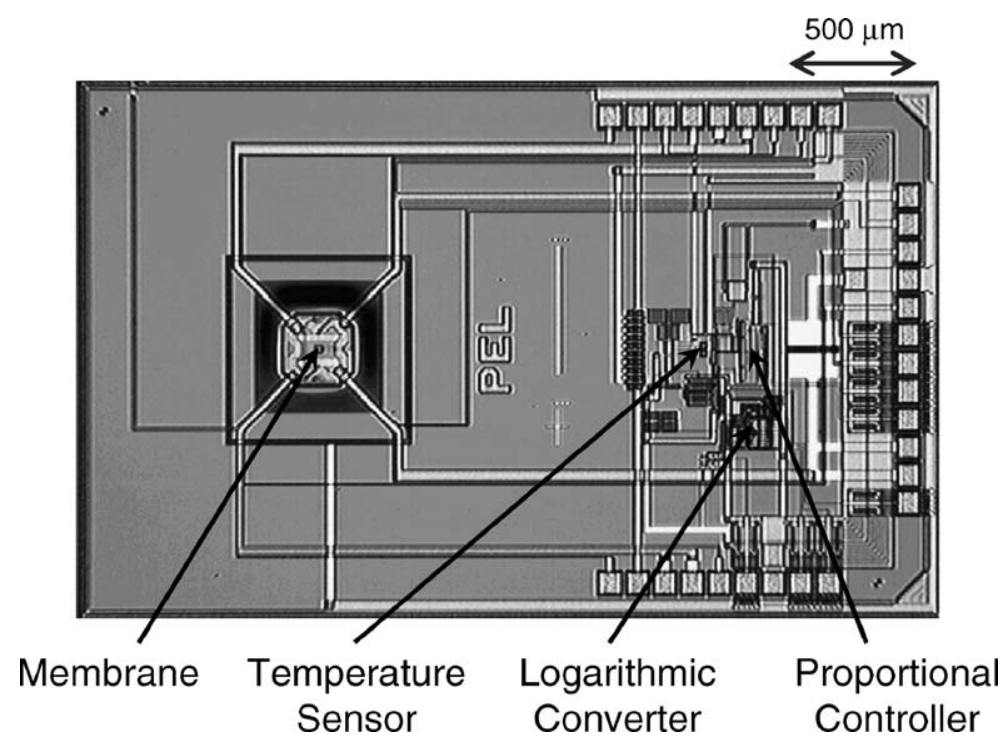

Fig. 1. Micrograph of the integrated chemical sensor chip. 


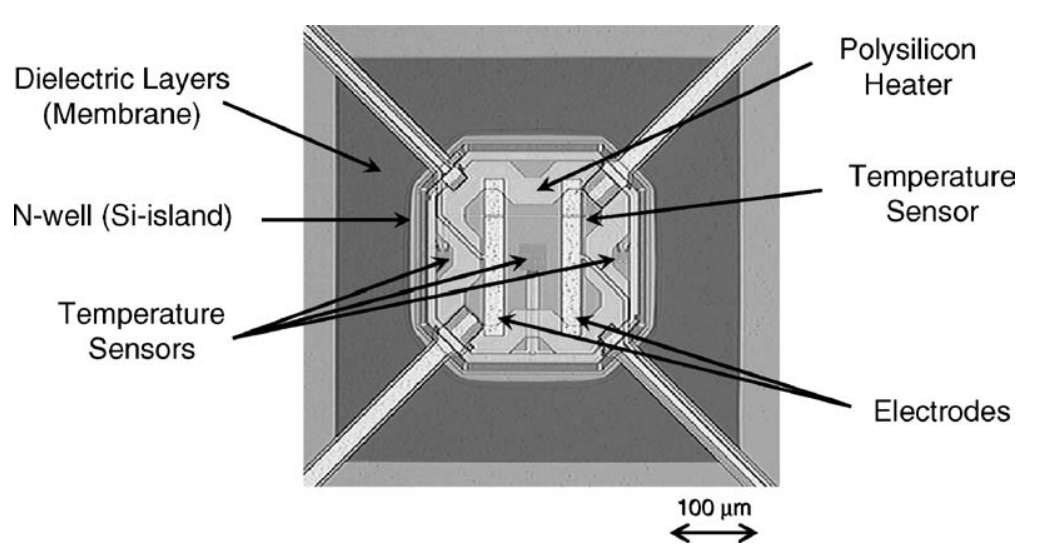

Fig. 2. Close-up of the microhotplate.

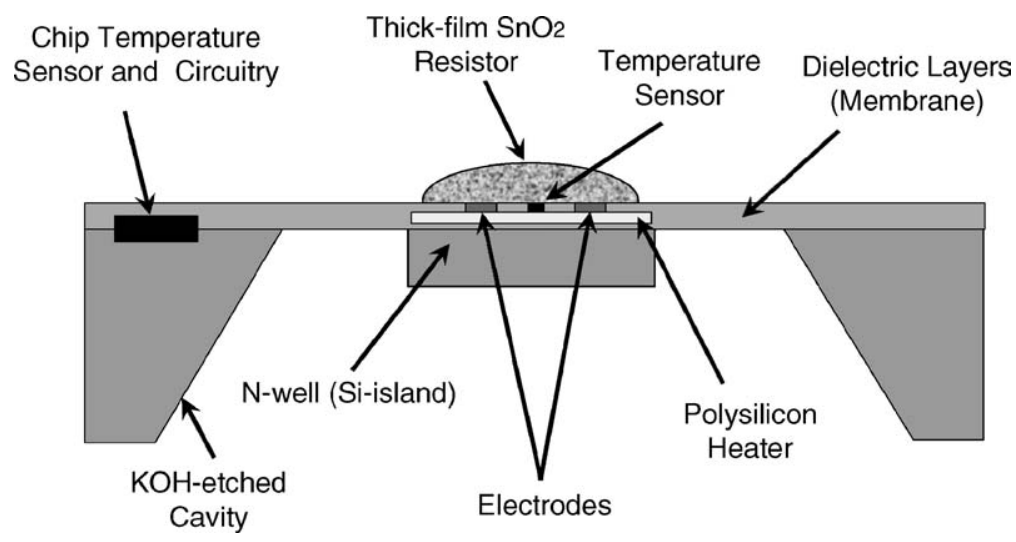

Fig. 3. Cross-section of the microhotplate.

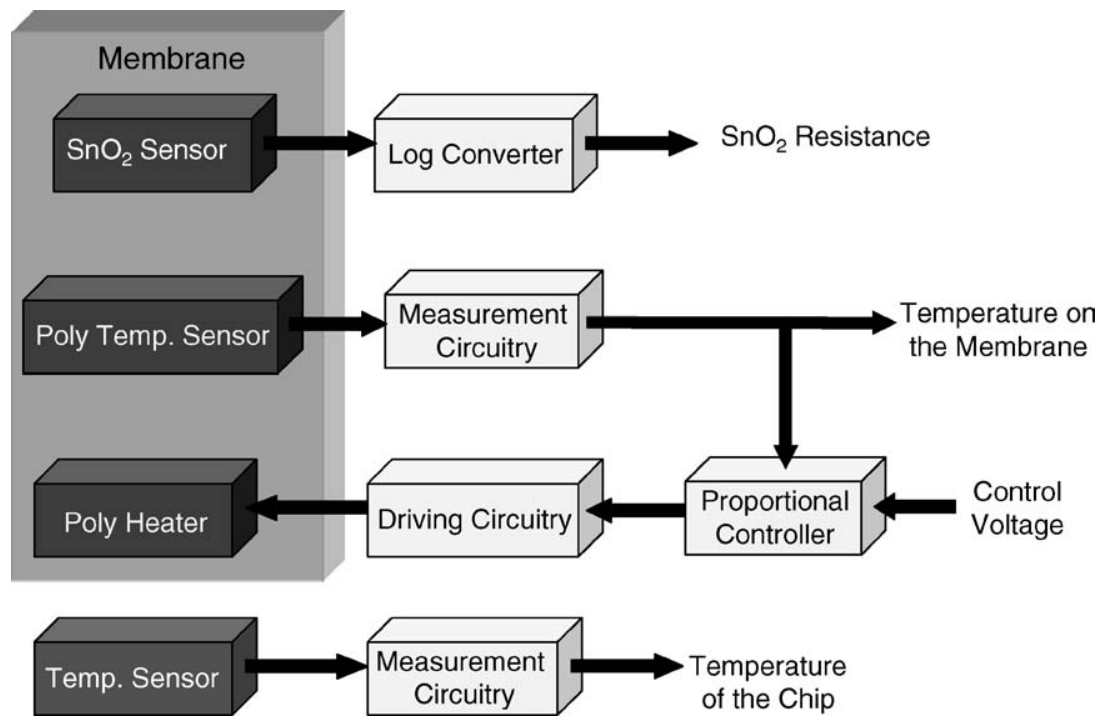

Fig. 4. Block diagram of the monolithic sensor system. 


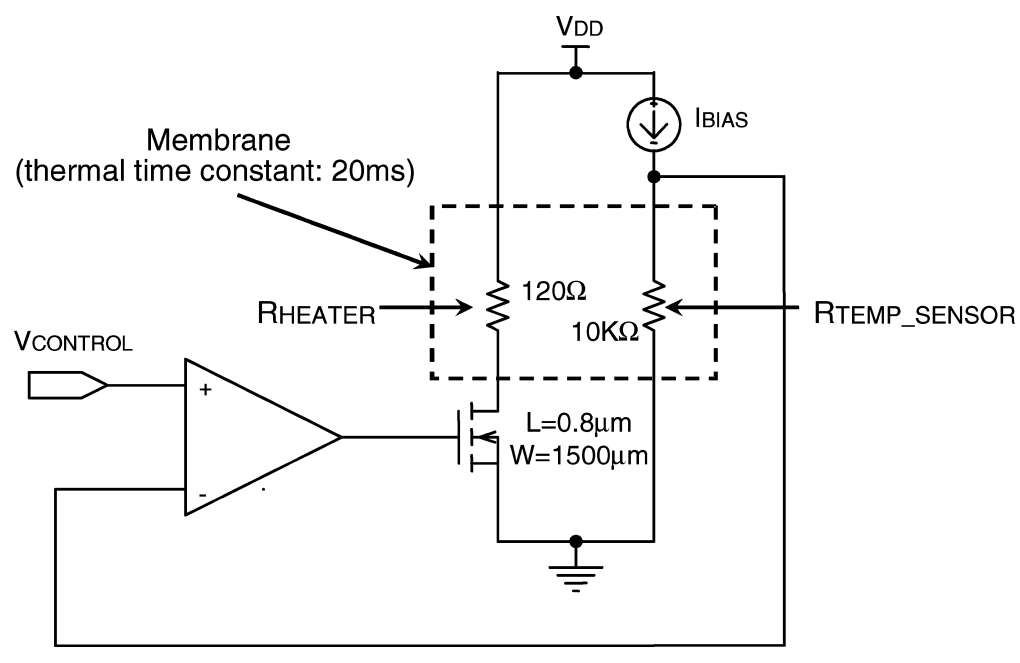

Fig. 5. Proportional temperature controller.

chip temperature measurement, and (iii) $\mathrm{SnO}_{2}$ resistance measurement. The chip is biased with an external current source (Hewelett Packard 3245A Universal Source), which is temperature-independent. This bias current is then copied and used for biasing the membrane temperature sensor, the reference current of the logarithmic converter and the bulk chip temperature measurement circuitry.

The proportional temperature controller (Fig. 5) is implemented with an operational amplifier $[20,21]$ and an internal stabilization capacitor of $8 \mathrm{pF}$. The membrane temperature is controlled from room temperature up to $350^{\circ} \mathrm{C}$. The operational amplifier drives a power transistor, which provides the current to the polysilicon heater $\left(R_{\text {HEATER }}\right)$. The inputs of the operational amplifier consist of the control voltage ( $\left.V_{\mathrm{CONTROL}}\right)$ and the voltage drop on the polysilicon temperature sensor ( $\left.R_{\text {TEMP_SENSOR }}\right)$, which provides the feedback signal for the temperature controller. The polysilicon temperature sensor is biased with a temperature-independent current $\left(I_{\mathrm{BIAS}}\right)$. The aging effects in the polysilicon temperature sensor cannot be compensated by the electronics on chip. The dominant pole of the temperature control system is determined by the thermal time constant of the membrane, which is approximately $20 \mathrm{~ms}$. An on-chip stabilization capacitor was included to cancel the low frequency pole of the operational amplifier.

The main advantage of the proportional temperature controller is that it occupies minimum silicon area. The most important trade-off in the design of the proportional controller is between its stability (phase margin) and the steady-state error. When the open-loop gain of the controller increases, the phase margin and the steady-state error decrease and vice versa. A good trade-off between stability (phase margin) and steadystate error was found to be an open-loop gain of $76 \mathrm{~dB}$, with a phase margin of approximately $88^{\circ}$.

The main source of error for the temperature controller is the steady-state error introduced by the offset voltage of the operational amplifier, which is independent of the open-loop gain of the system (i.e., the steady-state error introduced by the offset voltage of the operational amplifier does not decrease when the open loop gain increases). During calibration of the sensor, the offset voltage is compensated for at room temperature (i.e., the steady state error is compensated for at room temperature), but the temperature dependence of the offset voltage remains. The steady-state error measured over the sensor system operation temperature range (ambient temperature between -40 and $120^{\circ} \mathrm{C}$ ) is less than $1 \%$ of the membrane temperature.

The bulk chip temperature is assessed via the baseemitter voltage difference between a pair of diodeconnected vertical PNP transistors (parasitic transistors available in the CMOS process, collectors tied to substrate) working at different current densities (Fig. 6).

The resistance of the $\mathrm{SnO}_{2}$ sensitive layer can vary over a wide range (up to six decades) and is measured from $1 \mathrm{k} \Omega \mathrm{hm}$ to $10 \mathrm{M} \Omega \mathrm{hm}$ using a logarithmic converter (Fig. 7), which was implemented with a voltageto-current converter and a pair of diode-connected vertical PNP transistors. The dc level of the logarithmic 


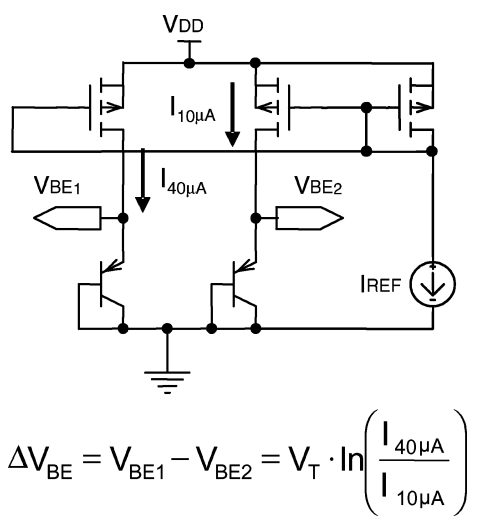

Fig. 6. Bulk chip temperature measurement circuitry.

converter can be changed with the reference current $\left(I_{\mathrm{REF}}\right)$. The bulk chip temperature is used to compensate for the temperature dependence of the logarithmic converter.

The circuitry is located at $1 \mathrm{~mm}$ distance from the micro-hotplate owing to packaging design considerations. A partial epoxy cover shields the circuitry and the bond wires from the environment, but enables free access of the analyte gas to the gas-sensitive material on the micro-hotplate.

\section{Simulation Results}

\subsection{Membrane Modeling Using an Analog Hardware Description Language (AHDL)}

The modeling of micro-electro-mechanical systems (MEMS) with hardware description languages (HDLs) supports the design and simulation of microsystems, which include MEMS-components and read-out electronics [22]. We modeled the thermo-electrical coupling between the heater and the membrane using the analog hardware description language (AHDL) provided by Cadence ${ }^{\mathrm{TM}}$ called SpectreHDL [23]. AHDL is a computer language that is specifically designed to enable high-level description and the behavioral simulation of continuous-time systems.

The model calculates the power dissipated by the polysilicon heater (Fig. 8). The calculated power serves as input for a look-up table with the measured values of the power dissipated by a normalized polysilicon resistor, which then provides the corresponding membrane temperature. The model extracts the membrane temperature from the table. This membrane temperature is subject to temporal delay according to the thermal time constant of the system. The membrane

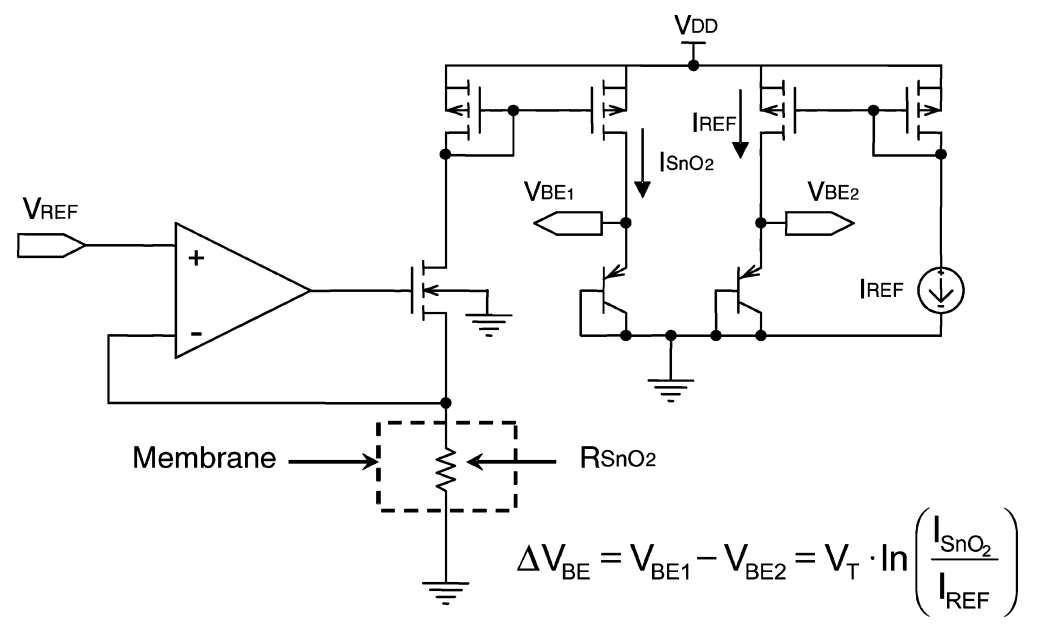

Fig. 7. Logarithmic converter.

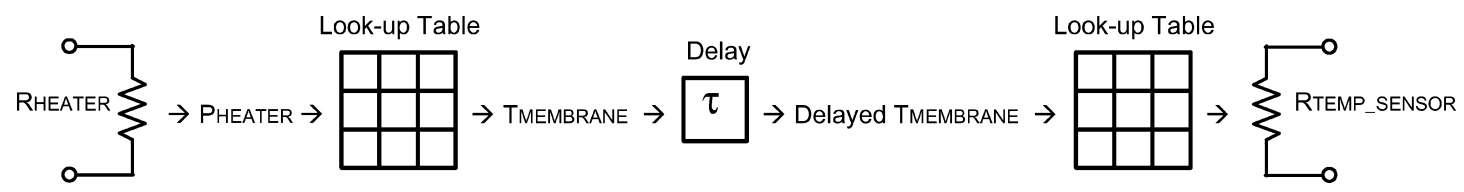

Fig. 8. Membrane modeling using AHDL. 
temperature then serves as input to another look-up table containing the measured values of the membrane temperature and the corresponding resistance value of a normalized polysilicon resistor. The model thereafter extracts the resistance value from the table and calculates the resistance of the polysilicon temperature sensor.

\subsection{Simulation of the Complete System}

The ADHL model was used for simulating the stability of the temperature controller. Figure 9 shows the Bode plots (magnitude and phase) of the output of the control system (voltage drop over the polysilicon temperature sensor). The phase margin is around $88^{\circ}$. The dominant pole at $8 \mathrm{~Hz}$ is resulting from the thermal time constant.

Transient simulations were done using a sinusoidal variation of the control voltage with an amplitude of $800 \mathrm{mV}$ around a common mode of $1 \mathrm{~V}$ and a frequency of $0.1 \mathrm{~Hz}$ (Fig. 10). Such low frequency of the control voltage was selected in the simulations because this frequency is commonly used in the temperature modulation mode of hotplate-based gas sensors (speed of the chemical reaction at the interface). The simulations show, that the circuitry can drive the membrane temperature to $350^{\circ} \mathrm{C}$ without distorting the shape given by the control voltage. When the control voltage is
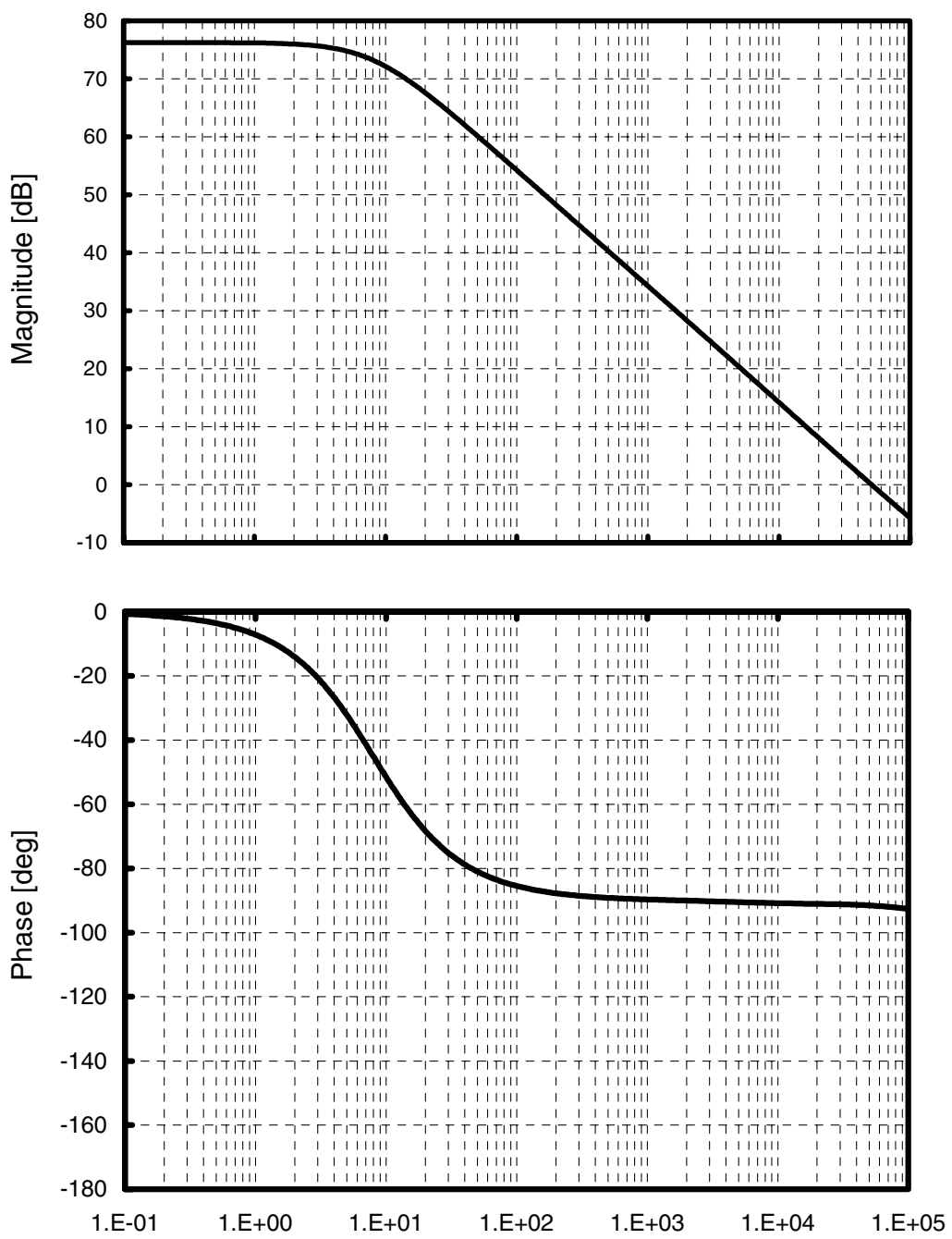

Fig. 9. Temperature controller: Bode plots—Magnitude and phase. 

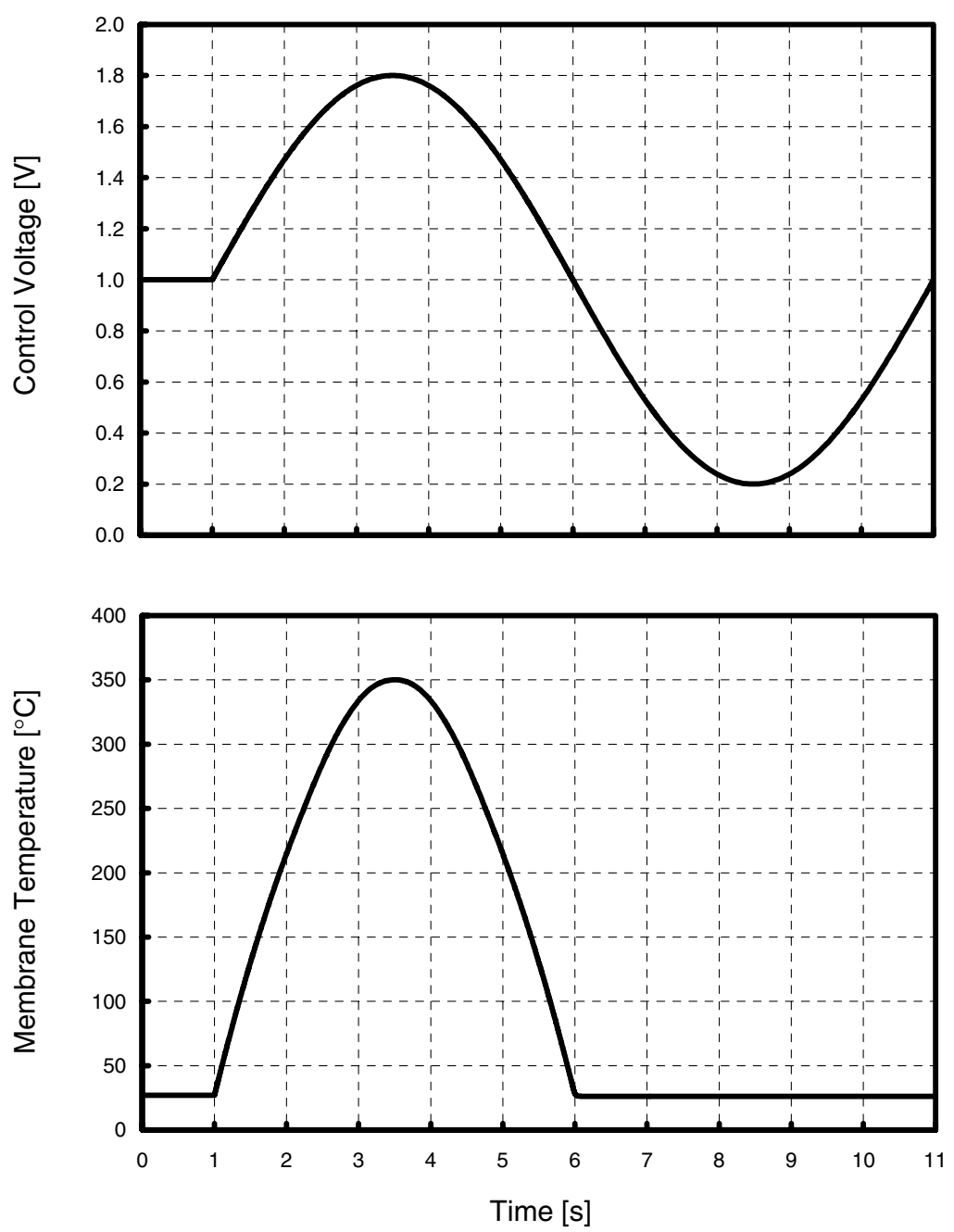

Fig. 10. Simulation of a sinusoidal control voltage variation and the corresponding membrane temperature response.

lower than the voltage drop across the polysilicon temperature sensor at ambient temperature (around $1 \mathrm{~V}$ at $27^{\circ} \mathrm{C}$ ), the membrane temperature equals ambient temperature. The simulations also show, that the simulated membrane temperature is $350^{\circ} \mathrm{C}$ for a control voltage of $1.8 \mathrm{~V}$, which results in an error of $2 \%$ in comparison to the measured membrane temperature (Fig. 11).

\section{Experimental Results}

\subsection{Electrical Measurements}

The tracking mode performance of the temperature controller was measured and is shown in Fig. 11. The measurement was done at room temperature, and the control voltage was increased in steps of $10 \mathrm{mV}$. A control voltage of $1.80 \mathrm{~V}$ produced, e.g., a membrane temperature of $343^{\circ} \mathrm{C}$. The measured sensitivity was about $0.63^{\circ} \mathrm{C} / \mathrm{mV}$. The controller showed an excellent performance with a resolution of $0.5^{\circ} \mathrm{C}$, which was assessed at the center temperature sensor of the membrane (temperature inhomogenities over the membrane were not taken into account).

The dynamic behavior of the temperature controller was assessed by subjecting the membrane to a temperature step from 27 to $300^{\circ} \mathrm{C}$. The temperature controller was found to be very stable showing no overshoot or ringing. 


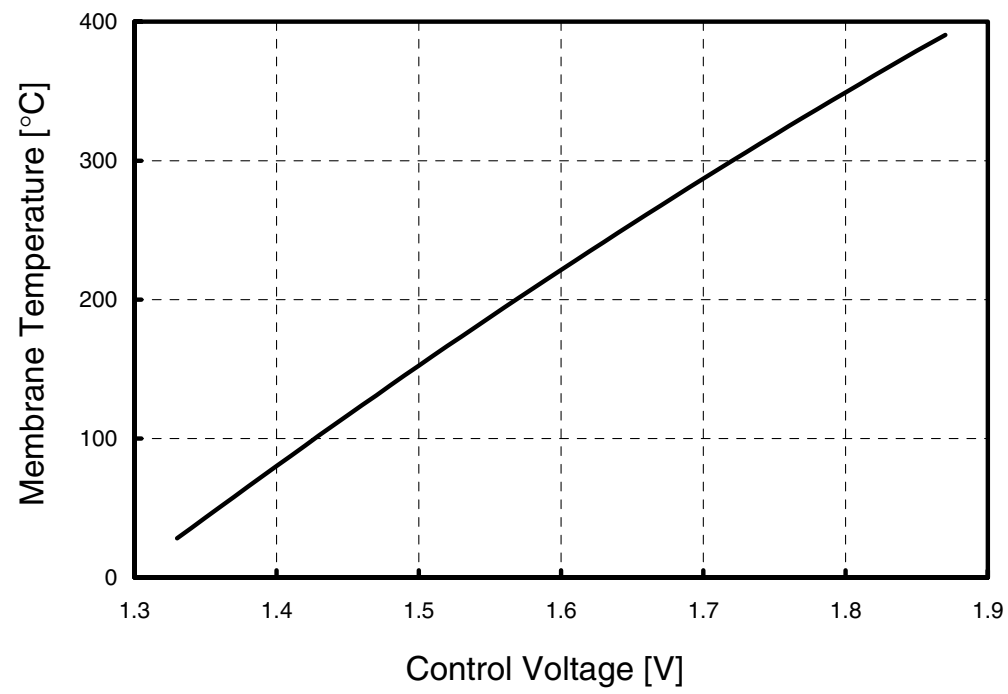

Fig. 11. Temperature controller in tracking mode.

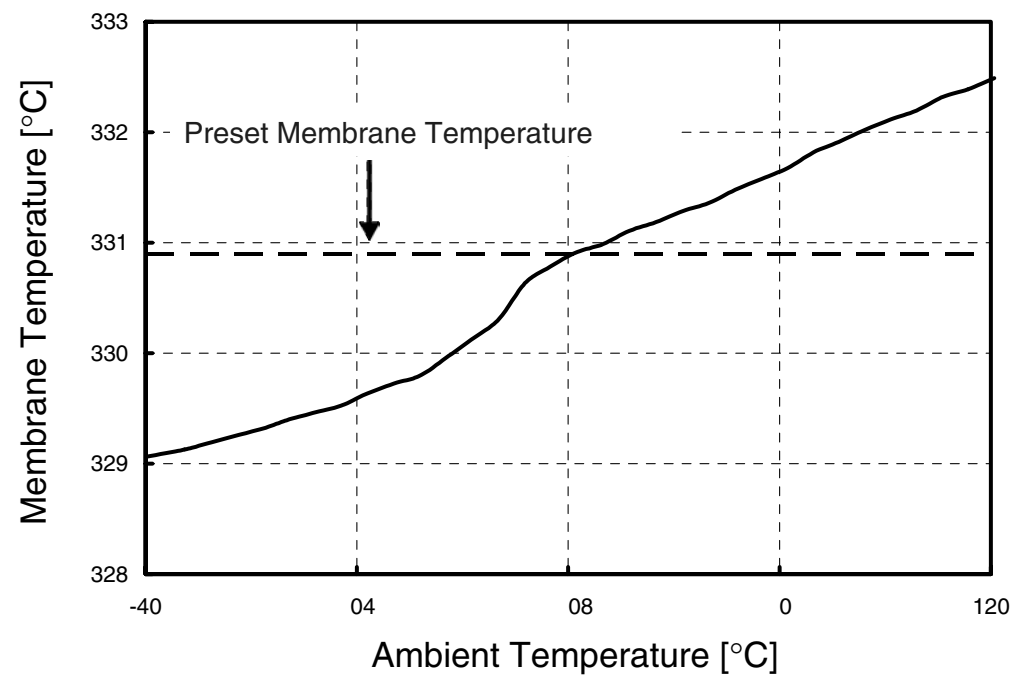

Fig. 12. Temperature controller in stabilization mode.

The performance of the temperature controller in the stabilization mode was also assessed (Fig. 12). The ambient temperature was ramped from -40 to $120^{\circ} \mathrm{C}$ in steps of $5^{\circ} \mathrm{C}$. A control voltage of $1.77 \mathrm{~V}$ was applied, which produced a membrane temperature of $330.9^{\circ} \mathrm{C}$. The steady-state error measured over the operating temperature range is less than $1 \%$ of the membrane temperature.

The performance of the temperature sensor on the bulk chip was also measured. The ambient temperature was swept from -40 to $120^{\circ} \mathrm{C}$ in steps of $5^{\circ} \mathrm{C}$, and the temperature controller was switched off. A twopoint calibration at -20 and $85^{\circ} \mathrm{C}$ was performed. The measured sensitivity was about $128 \mu \mathrm{V} /{ }^{\circ} \mathrm{C}$, and the resolution was $1.5^{\circ} \mathrm{C}$.

Finally temperature changes of the bulk chip owing to hotplate heating were assessed. The chip was mounted in a standard ceramic DIL package. The temperature discrepancy between ambient and the bulk silicon chip temperature was measured as a function of the membrane temperature (Fig. 13). The measurement was done at room temperature, and the control voltage 


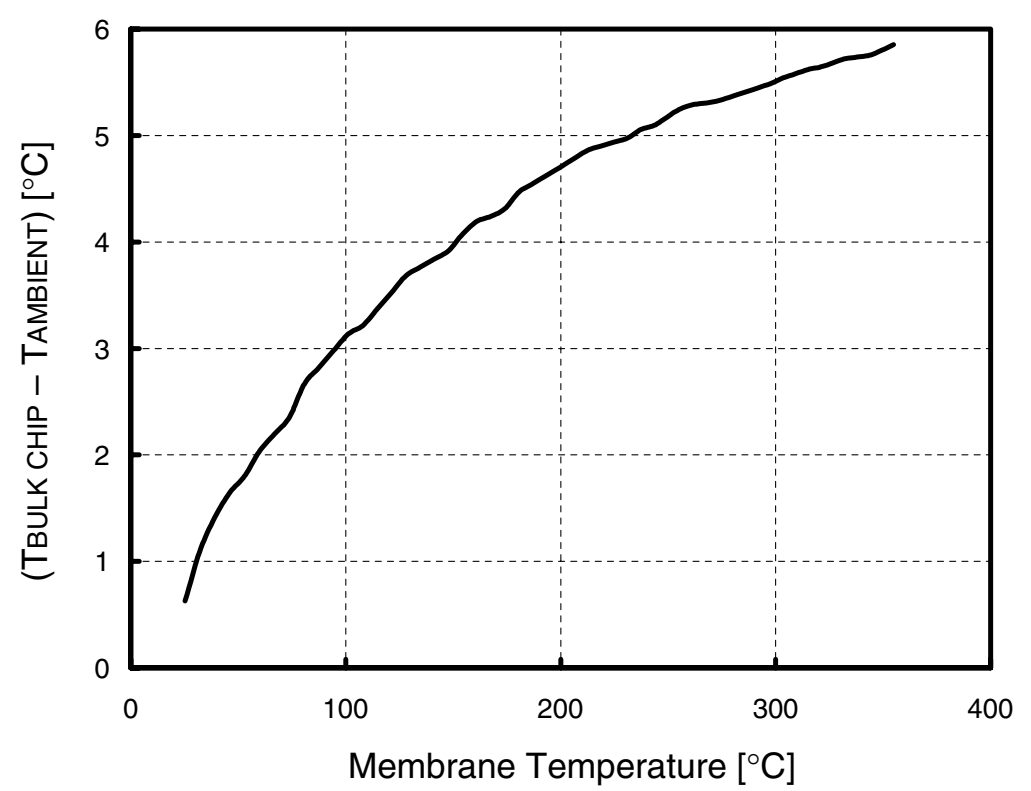

Fig. 13. Temperature discrepancy between ambient and bulk chip temperature as a function of the membrane temperature.

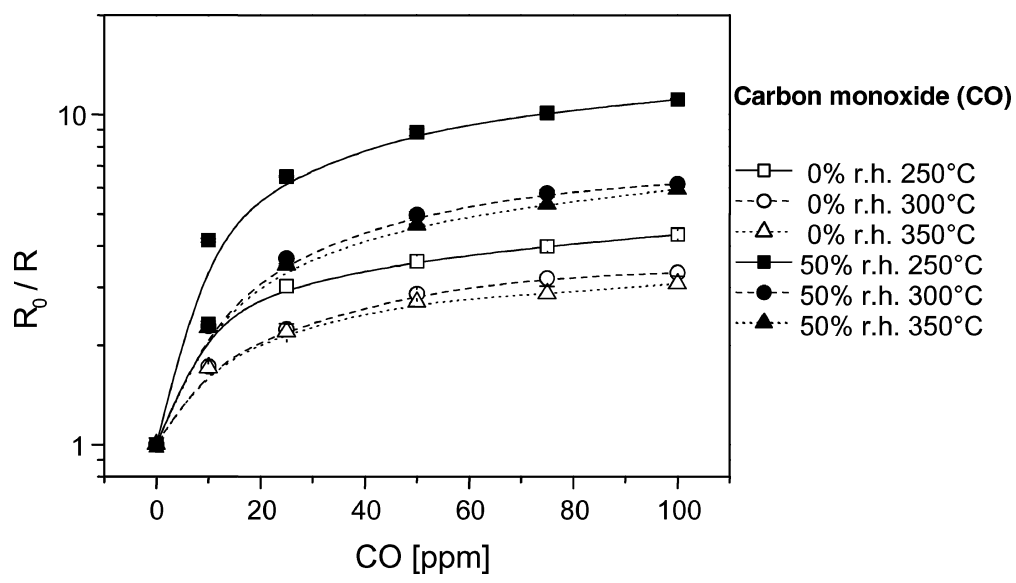

Fig. 14. Sensor response upon gas exposure to CO.

was increased in steps of $10 \mathrm{mV}$ heating the membrane from room temperature to $360^{\circ} \mathrm{C}$. The maximum temperature discrepancy between bulk chip and ambient temperature was less than $6^{\circ} \mathrm{C}$, which demonstrates the good thermal isolation between hotplate and bulk substrate.

\subsection{Chemical Measurements}

Gas test measurements were carried out with various concentrations of carbon monoxide $(\mathrm{CO})$ and methane
$\left(\mathrm{CH}_{4}\right)$ in air. Relative $\mathrm{SnO}_{2}$-resistance values $R_{0} / R$ were measured, with $R_{0}$ denoting the $\mathrm{SnO}_{2}$-resistance upon exposure to synthetic air (nitrogen-oxygen mixture), and $R$ denoting the $\mathrm{SnO}_{2}$-resistance upon exposure to the analyte gas. The $\mathrm{CO}$ concentrations ranged between 10-100 ppm (Fig. 14), and the $\mathrm{CH}_{4}$ concentrations between 750-10000 ppm (Fig. 15). The measurements were performed at relative humidities (r.h.) of 0 and $50 \%$. The sensor was operated between 250 and $350^{\circ} \mathrm{C}$ in steps of $50^{\circ} \mathrm{C}$. The gas flow rate was 0.2 liters per minute for all measurements. The 


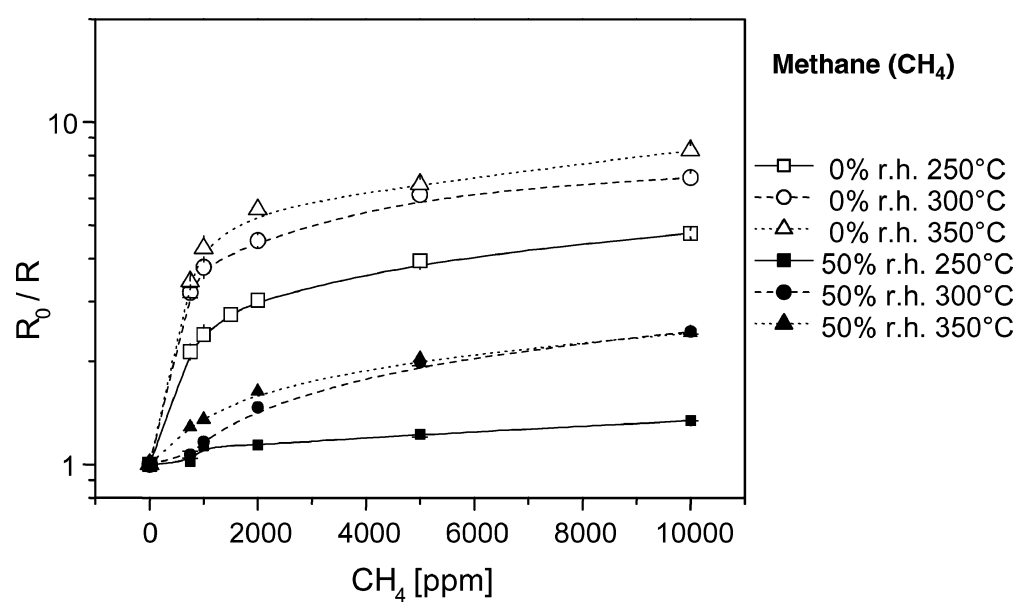

Fig. 15. Sensor response upon gas exposure to $\mathrm{CH}_{4}$.

exposure time of $30 \mathrm{~min}$ to the analyte gas is sufficient to achieve stable steady-state signals (response time approximately $30 \mathrm{~s}$ ). A recovery of the sensor is reached within $15 \mathrm{~min}$. The exposure time to pure carrier gas was set to $30 \mathrm{~min}$ to be on the safe side.

The sensor responses to $\mathrm{CO}$ and $\mathrm{CH}_{4}$ show different temperature dependence, which facilitates the quantitative detection of these compounds in a mixture using multi-component analysis methods.

Detectability of less than $1 \mathrm{ppm} \mathrm{CO}$ and less than 100 ppm $\mathrm{CH}_{4}$ enables the use of this chip in a wide range of applications.

\section{Conclusion and Outlook}

A monolithic gas sensor system fabricated in standard $0.8 \mu \mathrm{m}$ CMOS process combined with post-CMOS micromachining was presented. It comprises metal-oxidecovered $\left(\mathrm{SnO}_{2}\right)$ micro-hotplates and the necessary driving and signal-conditioning circuitry on the same chip.

The on-chip proportional temperature controller can accurately adjust the membrane temperature up to $350^{\circ} \mathrm{C}$ with a resolution of $0.5^{\circ} \mathrm{C}$. The steady-state error measured over the operating temperature range is less than $1 \%$ of the membrane temperature. The temperature controller is very stable and does not show any overshoot or ringing. The steady-state error in the operation temperature range can be further decreased if a proportional-integral-derivative (PID) temperature controller is used. The integral part will decrease the steady-state error, but it will also slow down the time response of the controller. This problem can be addressed with the derivative part of the controller.

The modeling of the membrane in AHDL can be used for design and simulation of the temperature controller without the need of changing the simulation environment.

The sensor system also exhibits excellent thermal isolation between heated membrane area and the circuitry area on the bulk chip (chip temperature rises by $\max 6^{\circ} \mathrm{C}$ at $350^{\circ} \mathrm{C}$ membrane temperature). The maximum temperature inhomogeneity on the membrane was $1-2 \%$ of the respective membrane temperature up to $350^{\circ} \mathrm{C}$, the power efficiency was $4.8^{\circ} \mathrm{C} / \mathrm{mW}$.

The logarithmic converter enables resistance measurements of the $\mathrm{SnO}_{2}$ sensitive layer between $1 \mathrm{k} \Omega \mathrm{hm}$ and $10 \mathrm{M} \Omega$ with an error of $\pm 1 \%$.

Gas tests yielded limits of detection below $1 \mathrm{ppm}$ $\mathrm{CO}$ and below $100 \mathrm{ppm} \mathrm{CH}_{4}$. The problems associated with poor selectivity and drift of individual gas sensors will be overcome by monolithic implementation of gas sensor arrays, which are based on the individual sensor design in this paper.

\section{Acknowledgments}

The authors would like to thank Advanced Sensing Devices (ASD) for coating the micro-hotplates, and Simone Hahn, University of Tübingen for conducting some of the gas test measurements. Financial Support was provided by the Bundesamt für Bildung und 
Wissenschaft, Bern (contract number 99-0135), and the European Union (contract number IST-1999-10579).

\section{References}

1. N. Bârsan and U. Weimar, "Conduction model of metal oxide gas sensors." Journal of Electroceramics, vol. 7, pp. 143-167, 2001.

2. I. Simon, N. Bârsan, M. Bauer, and U. Weimar, "Micromachined metal oxide gas sensors: Opportunities to improve sensor performance." Sensors and Actuators, vol. B 73, pp. 1-26, 2001.

3. V. Demarne and A. Grisel, "An integrated low-power thinfilm co gas sensor on silicon." Sensors and Actuators, vol. 13, pp. 301-313, 1988.

4. J.S. Suehle, R.E. Cavicchi, M. Gaitan, and S. Semancik, "Tin oxide gas sensor fabricated using CMOS micro-hotplates and in-situ processing." IEEE Electron Devices Letters, vol. 14, pp. 118-120, 1993.

5. S. Semancik, R.E. Cavicchi, M.C. Wheeler, J.E. Tiffany, G.E. Poirier, R.M. Walton, J.S. Suehle, B. Panchapakesan, and D.L. DeVoe, "Microhotplate platforms for chemical sensor research." Sensors and Actuators, vol. B 77, pp. 579-591, 2001.

6. D. Briand, A. Krauss, B. van der Schoot, U. Weimar, N. Barsan, W. Göpel, and N.F. de Rooij, "Design and fabrication of hightemperature micro-hotplates for drop-coated gas sensors." Sensors and Actuators, vol. B 68, pp. 223-233, 2000.

7. A. Götz, J. Gràcia, J.A. Plaza, C. Cané, P. Roetsch, H. Böttner, and K. Seibert, "A novel methodology for manufacturability of robust CMOS semiconductor gas sensor arrays." Sensors and Actuators, vol. B 77, pp. 395-400, 2001.

8. N. Najafi, K.D. Wise, R. Merchant, and J.W. Schwank, "An Integrated multi-element ultra-thin-film gas analyzer." Digest IEEE Solid-State Sensor and Actuator Workshop, pp. 19-22, 1992.

9. G.C. Cardinali, L. Dori, M. Fiorini, I. Sayago, G. Faglia, C. Perego, G. Sberveglieri, V. Liberali, F. Maloberti, and D. Tonietto, "A smart sensor system for carbon monoxide detection.” Analog Integrated Circuits and Signal Processing, vol. 14, pp. 275-296, 1997.

10. P.F. Rüedi, P. Heim, A. Mortara, E. Franzi, H. Oguey, and X. Arreguit, "Interface circuit for metal-oxide gas sensor." In IEEE 2001 Custom Integrated Circuits Conference, 2001, pp. 109-112.

11. D. Barrettino, M. Graf, M. Zimmermann, A. Hierlemann, H. Baltes, S. Hahn, N. Bârsan, and U. Weimar, "A smart singlechip micro-hotplate-based chemical sensor system in CMOStechnology." In Proceedings of the IEEE International Symposium on Circuits and Systems, 2002, vol. 2, pp. 157-160.

12. M.Y. Afridi, J.S. Suehle, M.E. Zaghloul, D.W. Berning, A.R. Hefner, S. Semancik, and R.E. Cavicchi, "A monolithic implementation of interface circuitry for CMOS compatible gassensor system." In Proceedings of the IEEE International Symposium on Circuits and Systems, 2002 vol. 2, pp. 732-735, and "A monolithic CMOS microhotplate-based gas sensor system." IEEE Sensors Journal, vol. 2, no. 6, pp. 644-655, 2002.

13. Y. Mo, Y. Okawa, K. Inoue, and K. Natukawa, "Low-voltage and low-power optimization of micro-heater and its on-chip drive circuitry for gas sensor array." Sensors and Actuators, vol. A 100, pp. 94-101, 2002.
14. A. Heilig, N. Bârsan, U. Weimar, M. Schweizer-Berberich, J.W. Gardner, and W. Göpel, "Gas identification by modulating temperatures of $\mathrm{SnO}_{2}$-based thick film sensors." Sensors and Actuators, vol. B 43, pp. 45-51, 1997.

15. T.A. Kunt, T.J. McAvoy, R.E. Cavicchi, and S. Semancik, "Optimization of temperature programmed sensing for gas identification using micro-hotplate sensors." Sensors and Actuators, vol. B 53, pp. 24-43, 1998.

16. A. Hierlemann, M. Schweizer-Berberich, U. Weimar, G. Kraus, A. Pfau, and W. Göpel, "Pattern recognition and multicomponent analysis.” Sensors Update, vol. 2, VCH, pp. 119-180, 1996.

17. austriamicrosystems, Unterpremstaetten, Austria. www. austriamicrosystems.com.

18. T. Müller, M. Brandl, O. Brand, and H. Baltes, "An industrial CMOS process family adapted for the fabrication of smart silicon sensors." Sensors and Actuators, vol. A 84, pp. 126-133, 2000.

19. M. Graf, D. Barrettino, M. Zimmermann, A. Hierlemann, H. Baltes, S. Hahn, N. Bârsan, and U. Weimar, "CMOS monolithic metal-oxide sensor system compromising a microhotplate and associated circuitry." IEEE Sensors Journal, vol. 4, pp. 9-16, 2004.

20. J.J.F. Rijns, "CMOS low-distortion high-frequency variablegain amplifier." IEEE Journal of Solid-State Circuits, vol. 31, no. 7, pp. 1029-1034, 1996.

21. R.J. Baker, H.W. Li, and D.E. Boyce, CMOS Circuit Design, Layout, and Simulation. IEEE Press, 1998.

22. D. Gibson, H. Carter, and C. Purdy, "The use of hardware description languages in the development of microelectromechanical systems." Analog Integrated Circuits and Signal Processing, vol. 28, pp. 173-180, 2001.

23. Cadence Design Systems, Inc., Spectre Reference, Introducing the spectre simulator, analog HDLs, Dec. 1998.

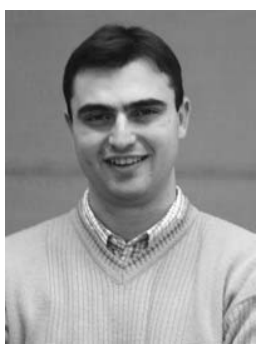

Diego Barrettino received the Dipl.-Ing. degree in electrical engineering from the University of Buenos Aires, Argentina, in 1997. From 1997 to 2000 he was employed by Allegro MicroSystems Argentina (formerly called Electrónica Bilotti), Buenos Aires, Argentina, where he was an analog IC designer for magnetic sensors. In April 2000, he joined the Swiss Federal Institute of Technology, Zurich, Switzerland, where he is working towards the Ph.D. degree in electrical engineering. His research interests are in the fields of analog and digital IC design, applications of control theory in the design of microsystems and MEMS-based microsensors. 


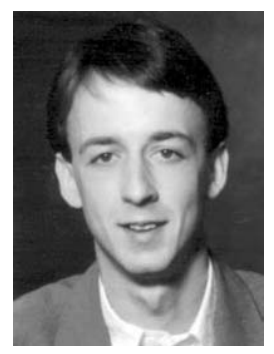

Markus Graf studied physics at the University of Konstanz, Germany and at the University JosephFourier in Grenoble, France and received a diploma degree in 1999. He worked as a research assistant at MIC (Microelectronic Center) in Lyngby, Denmark and joint the Physical Electronics Laboratory of ETH Zurich (Swiss Federal Institute of Technology), Switzerland. Currently he works towards a $\mathrm{PhD}$ degree. His research focuses on integrated chemical sensors and CMOScompatible micromachining.

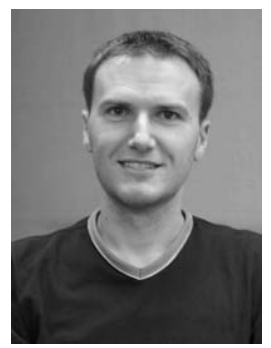

Martin Zimmermann received the bachelor's degree in electrical engineering from Technikum Rapperswil, Rapperswil, Switzerland, in 1996. Since 1996, he has been a Research Assistant at the Physical Electronics Laboratory at ETH Zurich. He is currently involved in the design of sensor front-end circuits and sensor on-chip systems.

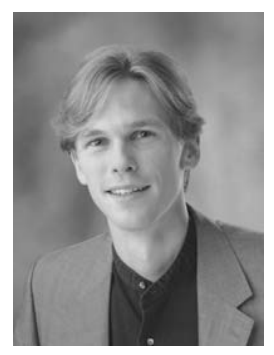

Christoph Hagleitner studied electrical engineering at the ETH Zurich and received his diploma in 1997. From 1997 to 2002 he worked as a research-assistant at the Physical Electronics Lab, ETH Zurich, received the $\mathrm{Ph} . \mathrm{D}$. degree in 2002 and is currently working there as a Postdoc. The focus of his research activities is on the system design and interface circuitry for smart sensors.

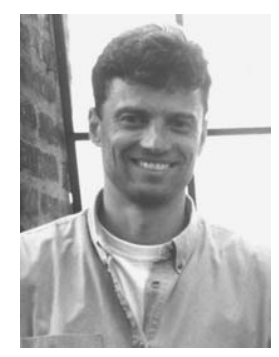

Andreas Hierlemann received his diploma in chemistry in 1992 and the Ph.D. degree in physical chemistry in 1996 from the University of Tübingen, Germany. After working as a Postdoc at Texas A\&M University, College Station, TX (1997), and Sandia National Laboratories, Albuquerque, NM (1998), he is currently a member of the technical staff at the ETH Zurich in Switzerland. The focus of his research activities is on chemical sensors and interfacial design.

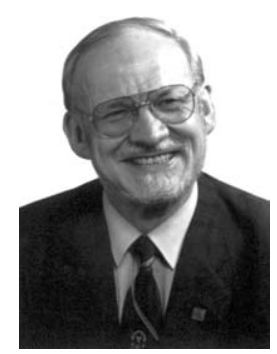

Henry Baltes, citizen of Canada, received the D.Sc. degree from ETH Zurich in 1971. In the following years he was on the faculty of the Freie Universität Berlin and the University of Düsseldorf, Germany, the University of Waterloo, Ontario, Canada, and EPF Lausanne, Switzerland.

From 1974 to 1982 he worked for Landis \& Gyr Zug, Switzerland, where he directed the solid-state device laboratory. From 1975 to 1982, he taught at EPF Lausanne. From 1983 to 1988, he held the Henry Marshall Tory Chair at the University of Alberta, Edmonton, Canada, where he directed a research program in microsensors. As acting President of the Alberta Microelectronic Centre he was in charge of establishing a CMOS metallisation fab. From 1986 to 1988, he was a Director of LSI Logic Corporation of Canada. 
Since 1988 he is Professor of Physical Electronics at ETH Zurich and Director of the Physical Electronics Laboratory active in silicon integrated microsystems. From 1992 to 1996 he was the Program Director of the Swiss national priority research program LESIT. In 1998 he received the Koerber Award. He is a co-founder of the spin-off company Sensirion, which won the Venture 98 Award for the Best Business Plan. Professor Baltes is Editor of "Sensors Update", Member of the
Swiss Academy of Technical Sciences, Swiss Management Association, Institute of Electrical and Electronic Engineers, Optical Society of America, Electrochemical Society, Institute of Physics (London), Swiss Society for Sensor Technology, Swiss Information Technology Society, Swiss Electrotechnical Association, Swiss Physical Society.

He is coauthor of about 500 technical publications, 15 patents, and 5 books. 